\title{
Numerical and Experimental Research on Thermal Insulation Performance of Marine Diesel Engine Piston Based on YSZ Thermal Barrier Coating
}

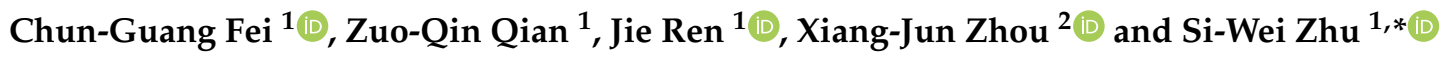 \\ 1 School of Energy and Power Engineering, Wuhan University of Technology, Wuhan 430063, China; \\ feicg419@whut.edu.cn (C.-G.F.); qzq@whut.edu.cn (Z.-Q.Q.); j.ren@whut.edu.cn (J.R.) \\ 2 Technical Center, Dongfeng Commercial Vehicle Co. Ltd., Wuhan 430056, China; zhouxiangjun@dfcv.com.cn \\ * Correspondence: wutyjt@163.com
}

check for

updates

Citation: Fei, C.-G.; Qian, Z.-Q.; Ren,

J.; Zhou, X.-J.; Zhu, S.-W. Numerical

and Experimental Research on

Thermal Insulation Performance of

Marine Diesel Engine Piston Based on

YSZ Thermal Barrier Coating.

Coatings 2021, 11, 765. https://

doi.org/10.3390/coatings11070765

Academic Editors: Cecilia Bartuli and Alessandro Patelli

Received: 28 April 2021

Accepted: 23 June 2021

Published: 25 June 2021

Publisher's Note: MDPI stays neutral with regard to jurisdictional claims in published maps and institutional affiliations.

Copyright: (c) 2021 by the authors. Licensee MDPI, Basel, Switzerland. This article is an open access article distributed under the terms and conditions of the Creative Commons Attribution (CC BY) license (https:// creativecommons.org/licenses/by/ $4.0 /)$.

\begin{abstract}
Although YSZ ceramic coating has been used in the field of aeroengines for a long time to protect blades from high temperature erosion, its application on marine engines is still very rare. In this study, YSZ powder was sprayed onto the upper surface of the Al-Si alloy piston by atmospheric plasma spraying. The piston with or without ceramic coatings was applied to the diesel engine bench, and the ship propulsion characteristics test was carried out to study the effect of the coating on the performance of the diesel engine when the ship was sailing. The temperature field results show that under $25 \%$ load, the temperature of the top surface of the coated piston is about $30.91{ }^{\circ} \mathrm{C}$ higher than that of the conventional piston. The increase in the temperature of the combustion chamber is conducive to better combustion of the fuel in the cylinder of the diesel engine. Therefore, when the marine diesel engine is tested for propulsion characteristics, the thermal efficiency is increased by $5 \%$ under the condition of $25 \%$ load.
\end{abstract}

Keywords: marine diesel engine piston; thermal barrier coating; thermal analysis; finite element method

\section{Introduction}

The main transportation method of global trade is still carried out by sea, and diesel engines are favored by ship power due to their high reliability. At present, diesel engines are in a leading position in the field of marine propulsion power [1]. If an innovation can effectively improve the thermal efficiency of marine diesel engines and reduce fuel consumption, it will have a positive impact on global trade. In order to improve the thermal efficiency of diesel engines, many studies have found that the ceramic thermal barrier coating (TBC) can well reduce the heat loss in the cylinder of the reciprocating internal combustion engine, thereby affecting the working performance of the engine [2,3].

With the continuous improvement of the power of marine diesel engines, the parts of the combustion chamber suffer more and more thermal damage, which has a great impact on the safe and stable operation of the engine. As the piston is the most important part of the combustion chamber of the engine, it is necessary to study the heat transfer of the piston to ensure the safe and reliable operation of the engine. Ceramic thermal barrier coating (TBC) has been widely used in blades of aircraft engines and gas turbines to protect the superalloy parts of the blades from high temperature and oxidation, thereby prolonging the service life of the engine [4-7]. The NiCrAlY coating is widely used in the bonding layer between the thermal insulation coating and the metal substrate because the coefficient of thermal expansion is between the metal substrate and the ceramic heat insulation layer [8]. In this study, NiCrAlY is also selected as the bonding layer of the coating. In addition, ceramic coatings can also provide thermal damage protection for the heated parts of the combustion chamber of marine diesel engines [9,10]. Hiregoudar [11] found that the use of coatings is more conducive to the combustion of low 16-paraffin fuels. The thickness of the 
coating and the coating process can affect the surface temperature of the piston, thereby affecting the combustion in the cylinder and having an impact on the fuel efficiency of the engine [12].

In this study, the atmospheric plasma spraying method was used to spray the TBC on the top surface of the piston, and the ship propulsion characteristics test research was carried out on the marine diesel engine. By comparing the test results of pistons with thermal barrier coatings to conventional pistons, the effect of coatings on the thermal efficiency of the engine is analyzed. In addition, this study presents finite element modeling of conventional diesel engine pistons and ceramic coating diesel engine pistons, and analyzes the effect of the TBC on the heat transfer of the piston by means of finite element simulation.

\section{Piston and Coating Materials}

The traditional material of internal combustion engine pistons is generally cast iron, but the density of cast iron pistons is relatively high, which makes the reciprocating inertia force of the piston at high speeds very large, thus restricting the development of internal combustion engine power. Therefore, the piston material of the medium and small power internal combustion engine is generally $\mathrm{Al}-\mathrm{Si}$ alloy. Due to the small proportion of aluminum alloy, which is about one-third of that of cast iron piston, the reciprocating inertia force produced by piston work will be greatly reduced.

The piston body used in this study is made of Al-Si alloy, and the ring groove is made of wear-resistant inlay made of cast iron (see Figure 1). In this way, the piston can have the characteristics of the light weight of Al-Si alloy pistons, and at the same time, it can avoid the jam fault due to the difference of thermal expansion performance between piston and piston ring. Although Al-Si alloy has good plasticity, it can make the piston bear more stress. However, aluminum alloys cannot withstand too high temperatures. This study provides the thermal insulation effect after spraying YSZ thermal barrier coating powder (see Figure 2) on the Al-Si alloy piston of a marine diesel engine. As shown in Figure 3, the top surface of the Al-Si alloy piston is coated with a YSZ ceramic thermal insulation coating, which completely covers the surface of the combustion chamber on the top surface of the piston. This greatly improves the reliability of the piston at high temperature.

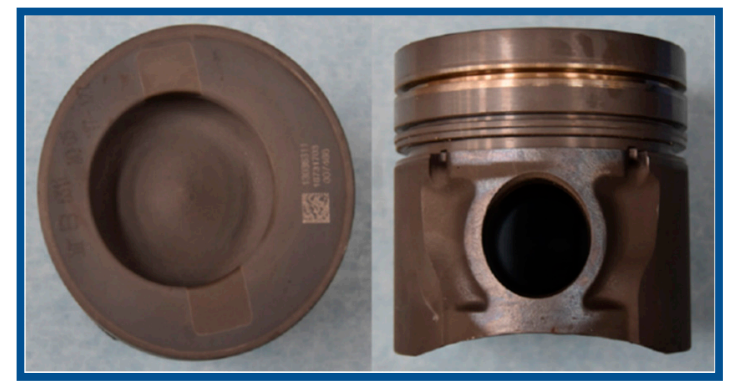

Figure 1. Conventional piston before spraying.

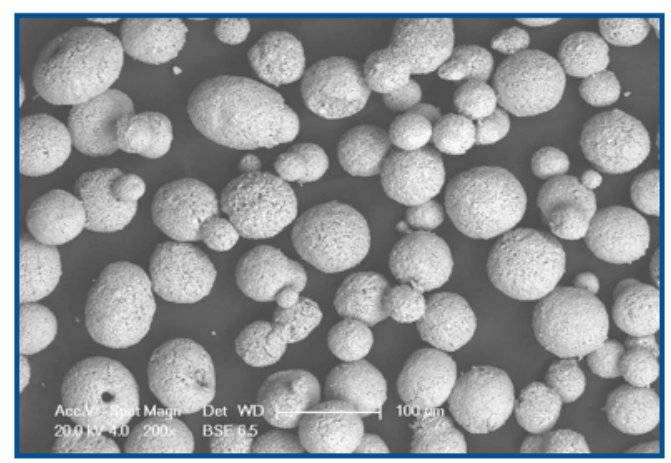

Figure 2. Microstructure of YSZ coating powder. 


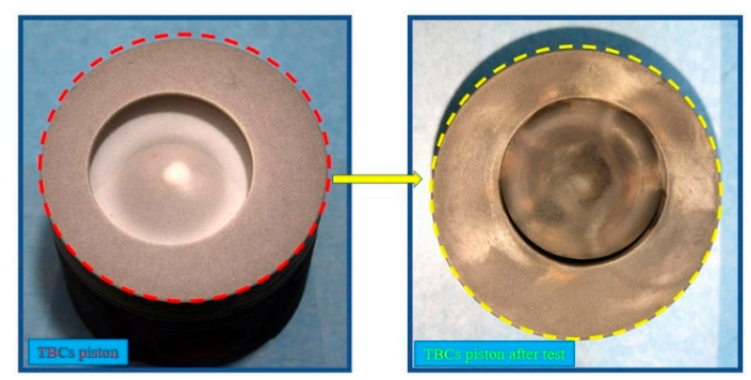

Figure 3. YSZ coated piston before and after test.

Due to its simple operation and high preparation efficiency, plasma spraying equipment is used in the preparation of most thermal barrier coatings [13-17].

The YSZ ceramic coatings are used as thermal insulation coatings because of their low thermal conductivity and relatively high coefficient of thermal expansion, thereby reducing harmful coating interface stress. In this study, a two-layer thermal barrier coating system with a thermal barrier layer and bonding layer was used (see Figure 4). The top coating comprises a $300 \mathrm{~mm}$ thick YSZ ceramic. The second layer is a bond coating containing a $100 \mathrm{~mm}$ thick NiCoCrAlY compound (see Figure 5).

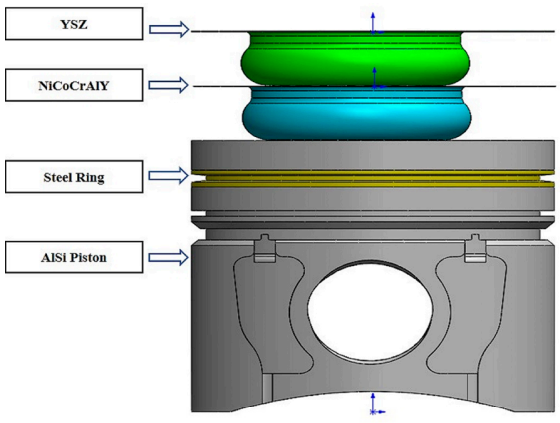

Figure 4. Thermal barrier coating piston model.

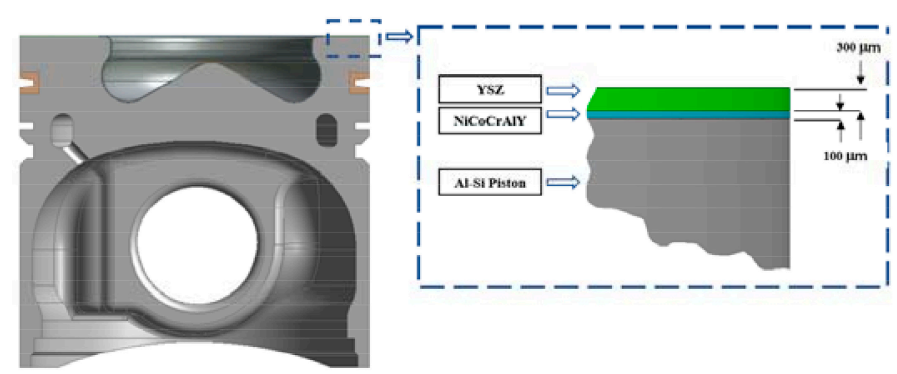

Figure 5. The half piston model and thermal barrier coating thickness.

Before spraying the thermal barrier coating, it is necessary to cut the top surface of the piston to ensure that the compression ratio of the engine remains unchanged.

\section{Simulation Analysis and Experimental Setup}

\subsection{Thermal Analysis by Finite Element Method}

Based on the marine diesel engine pistons made of Al-Si alloy and cast iron, this research conducted finite element thermal analysis on uncoated piston and coated piston.

The finite element model of this study uses a total of 4,382,973 elements and 7,783,387 nodes (see Figure 6). The meshing used for heat transfer analysis of YSZ coated piston is refined in ANSYS Workbench. In the thermal analysis, the material properties of YSZ barrier layer, bonding layer and piston substrate are taken from Table 1. The marine diesel engine piston issued is shown in Figures 1 and 3. Because the piston is axisymmetric, 
only half of the piston model is selected for simulation analysis in this paper. The half model of the piston and the coating thickness are shown in Figure 5.

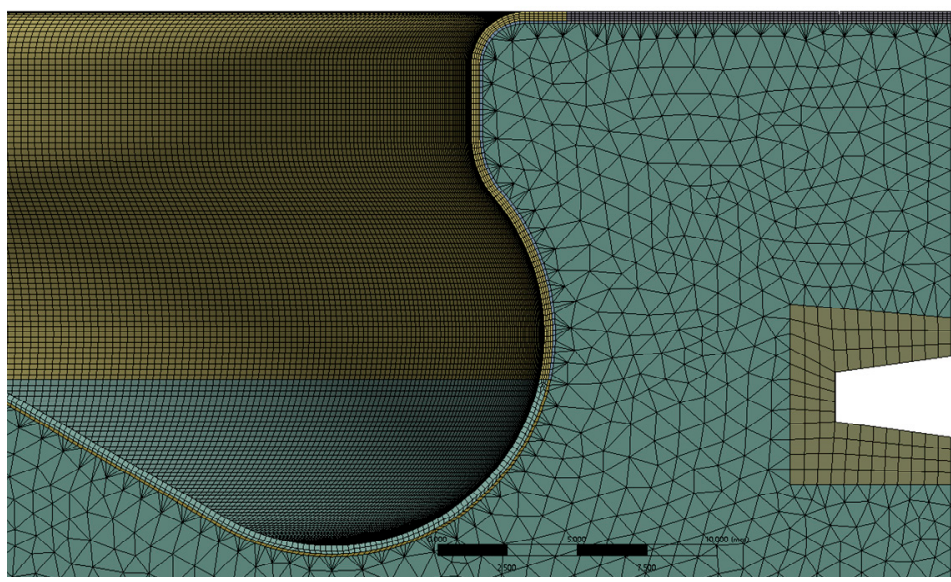

Figure 6. Finite element mesh of thermal barrier coating piston.

Table 1. The material properties of YSZ barrier layer, bonding layer and piston substrate.

\begin{tabular}{ccccccc}
\hline Material & $\begin{array}{c}\text { Thermal } \\
\text { Conductivity } \\
{\left[\mathbf{W} / \mathbf{m}^{\circ} \mathbf{C}\right]}\end{array}$ & $\begin{array}{c}\text { Thermal Expansion } \\
\mathbf{1 0}-\mathbf{6}\left[\mathbf{1} /{ }^{\circ} \mathbf{C}\right]\end{array}$ & $\begin{array}{c}\text { Density } \\
{\left[\mathbf{k g} / \mathbf{m}^{\mathbf{3}}\right]}\end{array}$ & $\begin{array}{c}\text { Specific Heat } \\
{\left[\mathbf{J} / \mathbf{k g}{ }^{\circ} \mathbf{C}\right]}\end{array}$ & $\begin{array}{c}\text { Young's } \\
\text { Modulus } \\
{[\mathbf{G P a}]}\end{array}$ & $\begin{array}{c}\text { Poisson's } \\
\text { Ratio }\end{array}$ \\
\hline Al-Si alloy & 155 & 21 & 2700 & 960 & 90 & 0.3 \\
Steel & 79 & 12.2 & 7300 & 500 & 600 & 0.3 \\
YSZ & 2.12 & 10.7 & 6010 & 640 & 40 & 0.22 \\
NiCoCrAlY & 16.1 & 17.5 & 7870 & 764 & 86 & 0.3 \\
\hline
\end{tabular}

The YSZ thermal barrier coating and NiCoCrAlY bond coating are sprayed on the top of the piston by air plasma spraying. The temperature distribution on different surfaces of the TBC piston is shown by simulation analysis, and their results are compared with those of the uncoated piston.

The thermal boundary conditions of the piston are very complicated, mainly including: the combustion chamber, the piston and the cooling oil cavity, the area between the piston and the cylinder liner, the bottom of the engine piston and the crankcase mixed gas. In this study, the thermal boundary conditions of the temperature and the heat transfer coefficient of the medium are calculated based on the empirical formula and the experimental measured values under the maximum power situation.

Because the analysis of the piston temperature field is often performed under the maximum load, this article collects relevant data and calculates the relevant boundary conditions when the engine speed is $945 \mathrm{rpm}$ and the load is $15 \mathrm{~kW}$.

In this way, thermal boundary conditions of the different elements are shown in Table 2. The surface temperature of the combustion chamber on the top surface of the piston was estimated to be $460{ }^{\circ} \mathrm{C}$, and the corresponding convection coefficient was $507 \mathrm{~W} / \mathrm{m}^{2} \mathrm{~K}$. The temperature of the piston fire shore position was assumed to be $130{ }^{\circ} \mathrm{C}$ with a convection coefficient of $127 \mathrm{~W} / \mathrm{m}^{2} \mathrm{~K}$. The temperatures of the upper, middle, and lower parts of the first ring were estimated to be $90{ }^{\circ} \mathrm{C}, 85^{\circ} \mathrm{C}$, and $85^{\circ} \mathrm{C}$, and the corresponding convection coefficients were $127 \mathrm{~W} / \mathrm{m}^{2} \mathrm{~K}, 73 \mathrm{~W} / \mathrm{m}^{2} \mathrm{~K}, 1261 \mathrm{~W} / \mathrm{m}^{2} \mathrm{~K}$, respectively. The temperature of the second ring was estimated to be $80{ }^{\circ} \mathrm{C}$, and the corresponding convection coefficient was $326 \mathrm{~W} / \mathrm{m}^{2} \mathrm{~K}$. The surface temperature of the piston skirt was specified as $75^{\circ} \mathrm{C}$, and the corresponding convection coefficient was $215.5 \mathrm{~W} / \mathrm{m}^{2} \mathrm{~K}$. The surface temperature of the cooling oil cavity of the piston was defined as $80{ }^{\circ} \mathrm{C}$, and the corresponding convection coefficient was $2000 \mathrm{~W} / \mathrm{m}^{2} \mathrm{~K}$. 
Table 2. Thermal boundary conditions of the different elements.

\begin{tabular}{ccc}
\hline Thermal Boundary Conditions & Temperature $\left({ }^{\circ} \mathbf{C}\right)$ & $\begin{array}{c}\text { Convective Heat Transfer } \\
\text { Coefficient }\left(\mathbf{W} / \mathbf{m}^{\mathbf{2}} \mathbf{K}\right)\end{array}$ \\
\hline Combustion chamber & 460 & 507 \\
Piston fire shore & 130 & 127 \\
Upper part of the first ring & 90 & 127 \\
Middle part of the first ring & 85 & 73 \\
Lower part of the first ring & 85 & 1261 \\
Second ring & 80 & 326 \\
Piston skirt & 75 & 215.5 \\
Cooling oil cavity & 80 & 2000 \\
\hline
\end{tabular}

\subsection{Experimental Setup}

In order to study the influence of thermal barrier coatings on diesel engines during ship voyage, the diesel engine test in this paper is a propulsion characteristic test carried out according to the working conditions of the ship. The engine used in this analysis was a WP4 direct-injection marine diesel engine equipped with a turbocharger. When the rated speed was $1500 \mathrm{rpm}$, the corresponding rated power was $60 \mathrm{~kW}$. The details of the test engine are given in Table 3.

Table 3. Specifications of test engine.

\begin{tabular}{ccc}
\hline NO. & Engine Parameters & Specifications \\
\hline 1 & Engine model & WP4 \\
2 & Number of cylinders & 4 \\
3 & Number of cycles & 4 \\
4 & Cooling type & Water-cooled \\
5 & Rated Speed & $1500 \mathrm{rpm}$ \\
6 & Bore Diameter & $105 \mathrm{~mm}$ \\
7 & Stroke & $130 \mathrm{~mm}$ \\
8 & Compression ratio & $18: 1$ \\
\hline
\end{tabular}

By comparing the experimental data of marine diesel engines with coated pistons to conventional pistons, the effect of coatings on the thermal efficiency of the engine is analyzed. The marine diesel engine bench is shown in Figure 7.

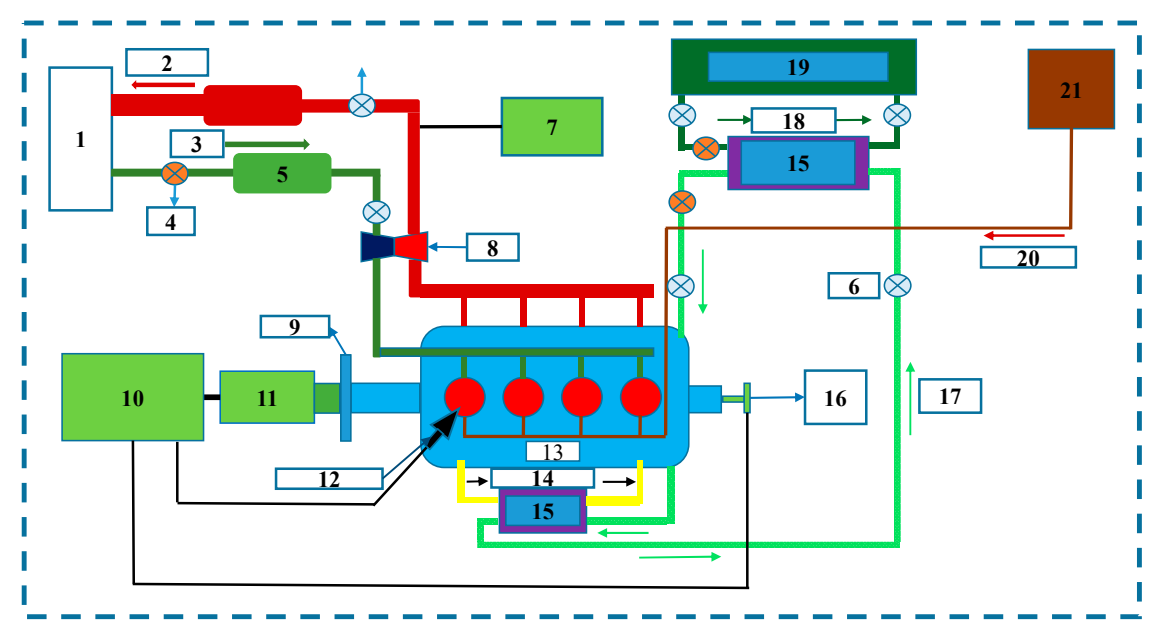

Figure 7. Schematic diagram of marine diesel engine test bench. 1-Outdoor, 2-Exhaust gas, 3-Air, 4-Flowmeter, 5-Air surge tank, 6-Thermometer, 7-Emission analyzer, 8-Turbocharger, 9-Coupling, 10-Combustion analyzer, 11-Dynamometer, 12-Pressure sensor, 13-Marine diesel engine, 14-Lubricating oil direction, 15-Heat exchanger, 16-Crank angle encoder, 17-Fresh water direction, 18-Sea water direction, 19-Sea water tank, 20-Fuel direction, 21-Fuel tank. 


\section{Results and Discussions}

\subsection{Temperature Measurements}

In this paper, the hardness plug made of GCr15 steel is used as the measuring method to measure the temperature value of the corresponding point on the piston. The hardness of GCr15 steel will change differently at different temperatures. The hardness plug after the test is taken out, and the maximum temperature of the hardness plug is reversed according to its Vickers hardness result. Due to the low temperature of the piston under 25\% load, in order to avoid the large measurement error of the hardness plug at low temperature, this paper calculates the highest temperature value of the corresponding point of the piston by measuring the result of the hardness plug under $50 \%$ load, then compares the experimental results with the simulation results to verify the reliability of the piston model. Figure 8 shows the location of reference points on the conventional piston. The temperature field of a conventional aluminum-silicon piston at $50 \%$ load can be seen in Figure 9.

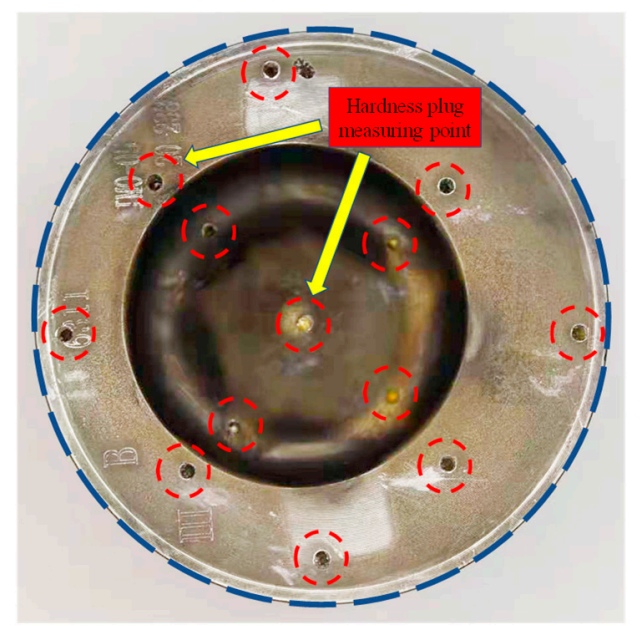

Figure 8. Distribution of temperature field reference points on conventional piston.
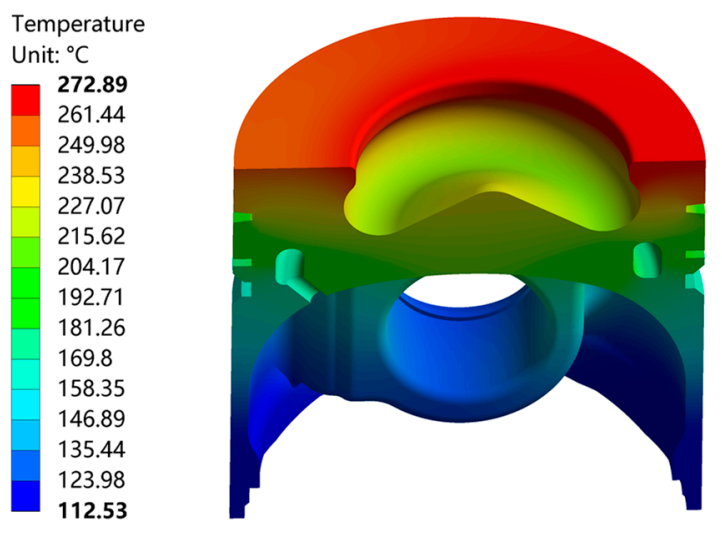

Figure 9. Temperature field of conventional Al-Si piston under $50 \%$ load.

\subsection{Comparison of Temperature Measurement Results}

The temperature results of the corresponding reference point of the piston under the $50 \%$ working condition of the simulation analysis were compared with the test results of the hardness plug, as shown in Figure 10. The deviation between these results is less than $6 \%$, which is within an acceptable range, indicating that the simulation results are highly accurate and reliable. 

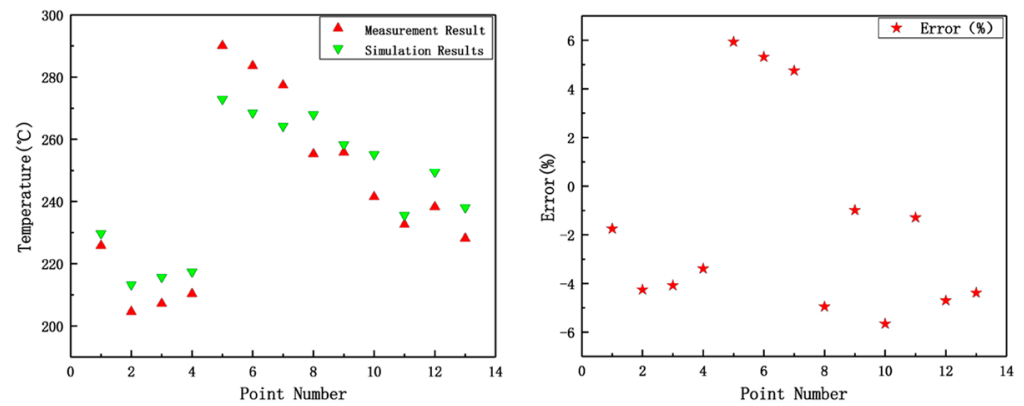

Figure 10. Comparisons between the simulations and measurement results.

\subsection{Temperature Distribution}

According to the established piston model, the temperature fields of the conventional and the thermal barrier coating piston were evaluated through numerical analysis, as shown in Figure 11.
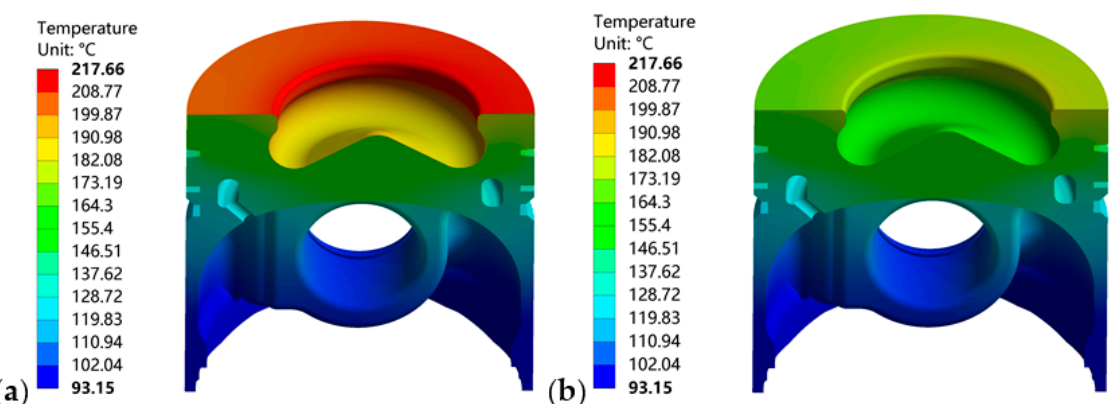

Figure 11. Temperature field of TBC piston: (a) the temperature field of the thermal barrier coating piston; (b) the temperature field of the thermal barrier coating piston substrate.

It can be seen from Figure 11a that the maximum temperature on the ceramic coating of the piston with thermal barrier coating reaches $217.66^{\circ} \mathrm{C}$, which appears in the throat ring area of the piston combustion chamber. Figure $11 \mathrm{~b}$ shows the temperature of the thermal barrier coating piston substrate; the maximum temperature of the piston is $182.24{ }^{\circ} \mathrm{C}$, and the lowest temperature is $93.15^{\circ} \mathrm{C}$.

The temperature is visually analyzed by selecting the path $\mathrm{AB}$ from point $\mathrm{A}$ on the edge of the piston top surface to point $B$ in the radial direction (shown by the line in Figure 12) and extracting the temperature value of the node on the path. The temperature values on the path $\mathrm{AB}$ of the top ceramic coating, the bonding layer and the top of the piston substrate of the TBC piston are shown in Figure $12 \mathrm{a}-\mathrm{c}$, respectively.

Analyzing the path analysis of the temperature field distribution of the thermal barrier coating piston in Figure 12d, it is apparent that the temperature of the TBC piston is the highest in the top ceramic coating, and the temperature gradient is larger between the ceramic coating and the bonding layer. The temperature difference between the bonding layer and the piston substrate is relatively small.

The simulation analysis of the temperature field distribution cloud diagram of the engine piston without thermal barrier coating is shown in Figure 13. Comparing Figures 11 and 13, it can be seen that after the marine diesel engine piston is processed by thermal barrier coating, the highest temperature of the piston drops from 186.75 to $182.24{ }^{\circ} \mathrm{C}$, therefore the temperature is reduced by $4.5^{\circ} \mathrm{C}$.

Through performing comparative analysis of the temperature field cloud diagram of the piston substrate with TBC (see Figure 11b) and that of the piston without TBC (see Figure 13), and using the software to extract the temperature value of the node on the path $A B$, the temperature distribution of the path $A B$ at the top edge of the piston with or without TBC was obtained as shown in Figures 12 and 14. 


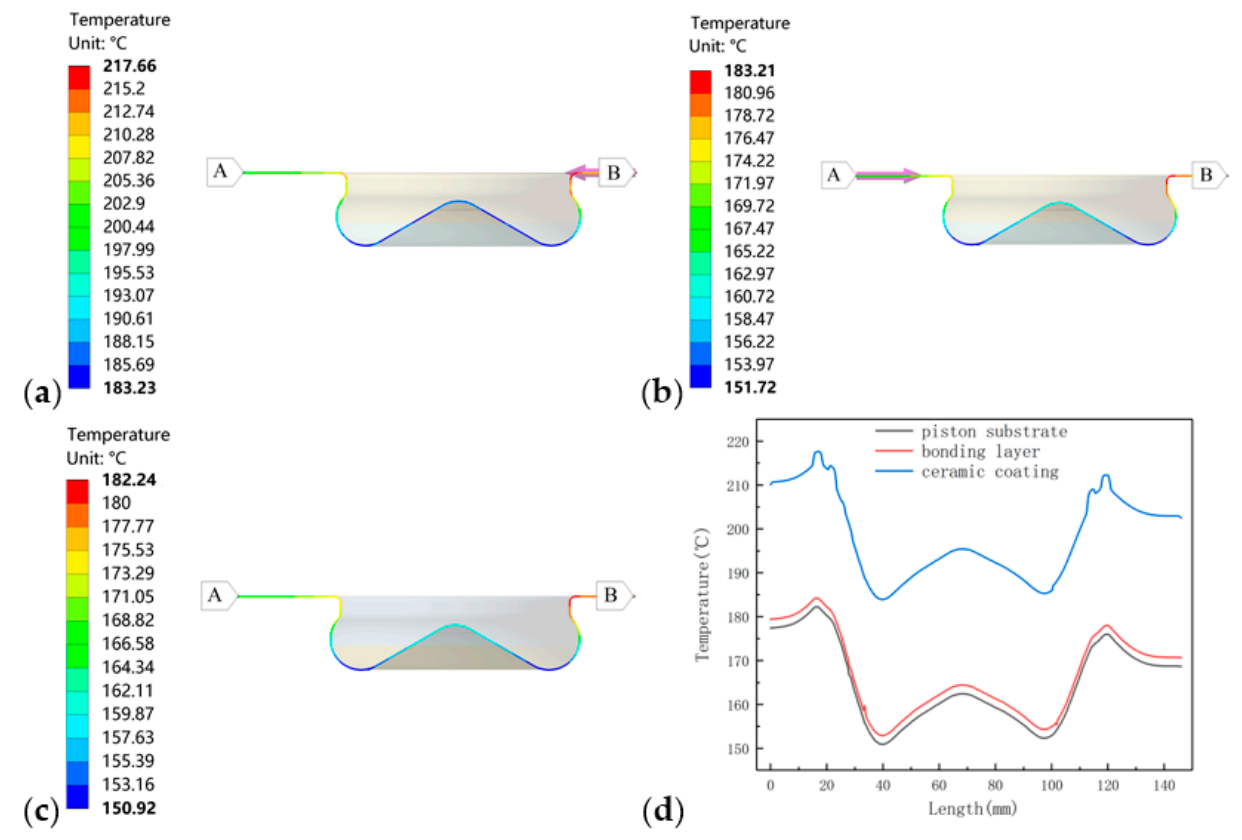

Figure 12. Path AB of TBC piston: (a) the top ceramic coating; (b) the bonding layer; (c) the top of the piston substrate; (d) the temperature distribution of the heat ceramic coating, the bonding layer and the piston substrate, respectively, along the path $\mathrm{AB}$.

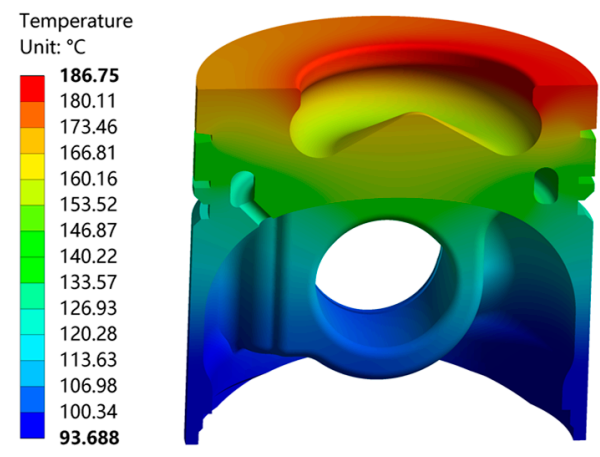

Figure 13. Temperature field of conventional Al-Si piston under 25\% load.

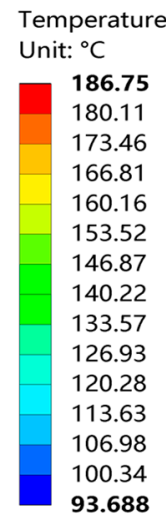

Figure 14. Path $\mathrm{AB}$ of conventional Al-Si piston.

Figure 15 shows the temperature value of the node on the path $\mathrm{AB}$. The red line indicates the temperature of the uncoated piston substrate, and the black line indicates the temperature of the piston substrate after spraying the coating. It can be seen from the figure that the highest temperature is at the throat of the piston combustion chamber of the 
diesel engine. After the marine diesel engine piston is processed by the thermal barrier coating, the temperature of the Al-Si alloy engine piston substrate decreases significantly, indicating that the thermal damage to the piston substrate is lower, which is better than the piston without TBC.

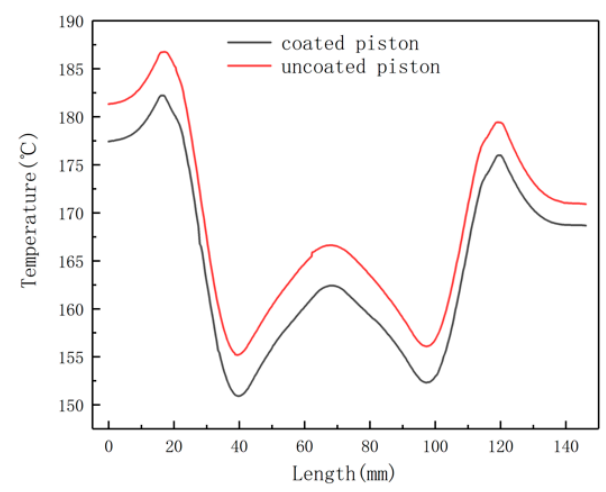

Figure 15. The temperature distribution along the $A B$ path. Red indicates the temperature of the uncoated piston substrate, and black indicates the temperature of the piston substrate after spraying the coating.

\subsection{The Effect of Coating on Thermal Efficiency}

Due to the heat insulation effect of the TBC, the heat transfer loss of the engine through the end face of the piston combustion chamber is reduced, thereby enhancing the brake thermal efficiency of the diesel engine [18-21].

In this research, by applying the piston sprayed with YSZ barrier coating to the marine diesel engine bench, the ship propulsion characteristics test was carried out to study the effect of the coating on the performance of the diesel engine when the ship was sailing.

The brake specific fuel consumption (BSFC) is the fraction between fuel mass consumption rate $\left(m_{f}\right)$ and brake power $\left(P_{b}\right)$, obtained from:

$$
\mathrm{BSFC}=\frac{m_{f}}{P_{b}}
$$

The brake thermal efficiency $\left(\eta_{t h}\right)$ is the ratio between produced work per cycle and chemical energy in the fuel, the calculation formula is as follows:

$$
\eta_{t h}=\frac{P_{b}}{Q_{H V} m_{f}}
$$

where $Q_{H V}$ is the fuel lower heating value.

In this test, six measurement points of ship propulsion characteristics were selected to carry out the test research, which are $25 \%, 50 \%, 75 \%, 80 \%, 90 \%$ and $100 \%$. Figure 16 a shows the BSFC comparison of uncoated and coated piston marine diesel engine under different propulsion characteristic loads. Figure 16b shows the change of engine braking thermal efficiency with the change of ship propulsion power.

It can be seen from Figure 16 that as the speed and load increase, the thermal efficiency of the coated engine will increase. Venkadesan's research also showed that pistons coated with TBC materials increase the break thermal efficiency due to reduction in heat loss and converts it into more available work, as the BTE increased by $8 \%$ [2]. Compared with the uncoated engine, the thermal efficiency of the piston engine coated with YSZ is increased by $5 \%$ and $2.2 \%$, respectively, under the conditions of low and medium load. At the same speed and load, the fuel consumption of the engine after adopting the YSZ ceramic coating is significantly reduced in the case of low and medium loads, indicating that the coated engine can achieve the same as the original engine while consuming less fuel. Combined with the temperature field analysis data, it is shown that the coating 
reduces the cooling loss of the engine and improves the thermal efficiency of the engine. Under high load conditions, because the surface temperature of the coating is too high, the air intake efficiency is reduced, and the thermal efficiency is not increased significantly.

(a)

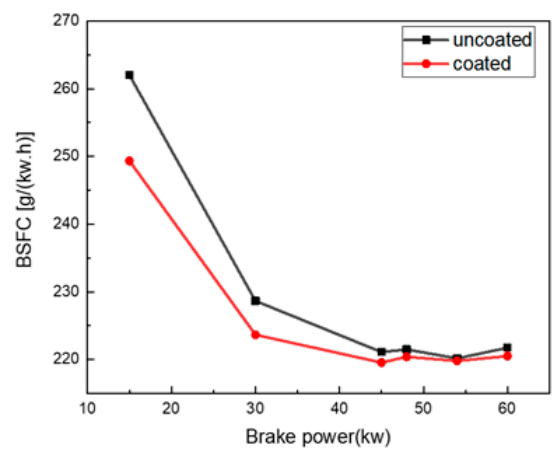

(b)

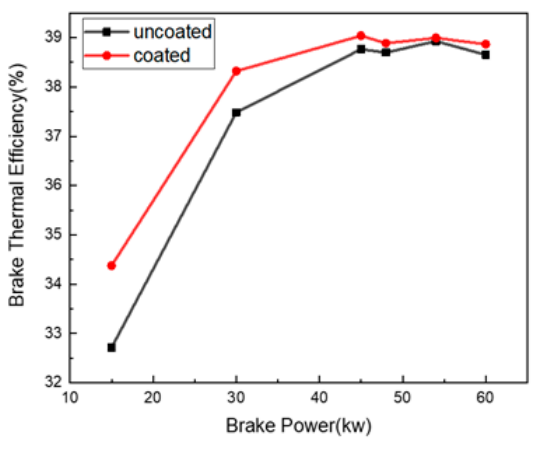

Figure 16. (a) brake power vs. brake specific fuel consumption; (b) brake power vs. brake thermal efficiency. Red line indicates the test results of diesel engine sprayed with YSZ coating, and black line indicates the test results of original engine.

\section{Conclusions and Future Work}

Through comparative analysis, it is found that the highest temperature on the top surface of the diesel engine piston always appears in the throat ring area of the combustion chamber. It has also been observed that the temperature of the top surface of the YSZ coated engine piston is higher than that of the uncoated engine piston. After the piston is coated, the maximum temperature of the piston substrate is about $4.5^{\circ} \mathrm{C}$ lower than that of the uncoated piston, indicating that the piston substrate suffers less thermal damage, which will have a positive impact on the reliability of the Al-Si alloy piston and engine life.

In addition, according to the propulsion characteristics test of the marine diesel engine, after adopting the YSZ ceramic coated piston, the fuel consumption of the coated engine is lower when the output is the same, especially under low load conditions. Compared with the uncoated engine, the YSZ-coated piston engine has the most improved thermal efficiency under low load conditions, with a maximum increase of $5 \%$. Therefore, this study shows that the YSZ coating can effectively improve the thermal efficiency of the diesel engine when the ship is sailing at medium and low speeds and has a positive effect on the development of the shipping industry.

Since this study only considered $300 \mu \mathrm{m}$ thick YSZ coatings, coating applications of different thicknesses and materials will be developed on marine engines in the future to provide an evaluation basis for finding the best coating application program.

Author Contributions: Conceptualization and formal analysis, C.-G.F.; investigation, X.-J.Z.; methodology, J.R.; supervision Z.-Q.Q.; writing—original draft preparation and supervision, S.-W.Z. All authors have read and agreed to the published version of the manuscript.

Funding: This research was funded by "the Fundamental Research for the Central Universities", grant number 2018-JL-002 and The APC was funded by "Hubei Province Technological Innovation Project".

Institutional Review Board Statement: Not applicable.

Informed Consent Statement: Not applicable.

Data Availability Statement: Data sharing not applicable.

Conflicts of Interest: The authors declare no conflict of interest. 


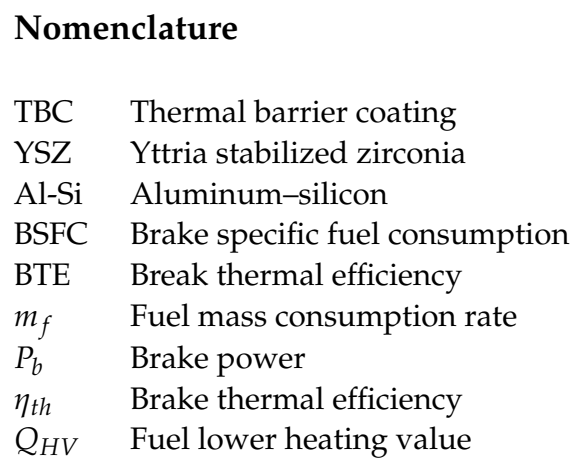

\section{References}

1. Kalghatgi, G. Is it really the end of internal combustion engines and petroleum in transport. Appl. Energy 2018, 225, 965-974. [CrossRef]

2. Venkadesan, G.; Muthusamy, J. Experimental investigation of $\mathrm{Al}_{2} \mathrm{O}_{3} / 8 \mathrm{YSZ}$ and $\mathrm{CeO}_{2} / 8 \mathrm{YSZ}$ plasma sprayed thermal barrier coating on diesel engine. Ceram. Int. 2019, 45, 3166-3176. [CrossRef]

3. Caputo, S.; Milloa, F.; Boccardoa, G.; Pianoa, A.; Cifali, G.; Pesce, F.C. Numerical and experimental investigation of a piston thermal barrier coating for an automotive diesel engine application. Appl. Therm. Eng. 2019, 162, 114-233. [CrossRef]

4. Darolia, R. Thermal barrier coatings technology: Critical review, progress up-date, remaining challenges and prospects. Int. Mater. Rev. 2013, 58, 315-348. [CrossRef]

5. Zhang, Y.; Malzbender, J.; Mack, D.E.; Jarligo, M.O.; Cao, X.; Li, Q.; Vaßen, R.; Stöver, D. Mechanical properties of zirconia composite ceramics. Ceram. Int. 2013, 39, 7595-7603. [CrossRef]

6. Jamali, H.; Mozafarinia, R.; Razavi, R.S.; Pidani, R.A. Comparison of thermal shock resistances of plasma-sprayed nanostructured and conventional yttria stabilized zirconia thermal barrier coatings. Ceram. Int. 2012, 38, 6705-6712. [CrossRef]

7. Shin, I.H.; Koo, J.M.; Seok, C.S.; Yang, S.H.; Lee, T.W.; Kim, B.S. Estimation of spallation life of thermal barrier coating of gas turbine blade by thermal fatigue test. Surf. Coat. Technol. 2011, 205, 157-160. [CrossRef]

8. Du, G.Y.; Tan, Z.; Li, G.H.; Ba, D.C.; Liu, K. Damping properties of arc ion plating NiCrAlY coating with vacuum annealing. Coatings 2018, 8, 20. [CrossRef]

9. Buyukkaya, E.; Cerit, M. Thermal analysis of a ceramic coating diesel engine piston using 3-D finite element method. Surf. Coat. Technol. 2007, 202, 398-402. [CrossRef]

10. Buyukkaya, E. Thermal analysis of functionally graded coating Al-Si alloy and steel pistons. Surf. Coat. Technol. 2008, 202, 3856-3865. [CrossRef]

11. Hiregoudar, Y.; Manjunatha, K. Combustion analysis of modified inverted " $\mathrm{M}$ " type piston for diesel engine with platinum coating and without coating by using CFD. Mater. Today Proc. 2017, 4, 2333-2340.

12. Sachit, T.S.; Nandish, R.V. Thermal analysis of $\mathrm{Cr}_{2} \mathrm{O}_{3}$ coated diesel engine piston using FEA. Mater. Today Proc. 2018, 5, 5074-5081. [CrossRef]

13. Zhu, C.; Li, P.; Javed, A.; Liang, G.Y.; Xiao, P. An investigation on the micro-structure and oxidation behavior of laser remelted air plasma sprayed thermal barrier coatings. Surf. Coat. Technol. 2012, 206, 3739-3746. [CrossRef]

14. Xie, S.M.; Song, C.; Yu, Z.X.; Liu, S.W.; Lapostolle, F.; Klein, D.; Deng, C.M.; Liu, M.; Liao, H.L. Effect of environmental pressure on the microstructure of YSZ thermal barrier coating via suspension plasma spraying. J. Eur. Ceram. Soc. 2021, 41, 535-543. [CrossRef]

15. Ashofteh, A.; Mashhadi, M.M.; Amadeh, A.; Seifollahpour, S. Effect of layer thickness on thermal shock behavior in double-layer micro-and nano-structured ceramic top coat APS TBCs. Ceram. Int. 2017, 43, 13547-13559. [CrossRef]

16. Daroonparvar, M.; Yajid, M.A.M.; Kay, C.M.; Bakhsheshi, H.; Gupta, R.K.; Yusof, N.M.; Ghandvar, H.; Arshad, A.; Zulkifli, I.S.M. Effects of $\mathrm{Al}_{2} \mathrm{O}_{3}$ diffusion barrier layer (including Y-containing small oxide precipitates) and nanostructured YSZ top coat on the oxidation behavior of HVOF NiCoCrAlTaY/APS YSZ coatings at $1100{ }^{\circ}$ C. Corros. Sci. 2018, 144, 13-34. [CrossRef]

17. Wang, L.; Wang, Y.; Sun, X.G.; He, J.Q.; Pan, Z.Y.; Wang, C.H. A novel structure design towards extremely low thermal conductivity for thermal barrier coatings-experimental and mathematical study. Mater. Des. 2012, 35, 505-517. [CrossRef]

18. Aydın, S.; Sayın, C. Impact of thermal barrier coating application on the combustion, performance and emissions of a diesel engine fueled with waste cooking oil biodiesel-diesel blends. Fuel 2014, 136, 334-340. [CrossRef]

19. Aydin, H. Combined effects of thermal barrier coating and blending with diesel fuel on usability of vegetable oils in diesel engines. Appl. Therm. Eng. 2013, 51, 623-629. [CrossRef]

20. Gehlot, R.; Tripathi, B. Thermal analysis of holes created on ceramic coating for diesel engine piston. Case Stud. Therm. Eng. 2016, 8, 291-299. [CrossRef]

21. Wang, Y.; Ma, T.Y.; Liu, L.; Yao, M.F. Numerical investigation of the effect of thermal barrier coating on combustion and emissions in a diesel engine. Appl. Therm. Eng. 2021, 186, 116497. [CrossRef] 